\title{
My approach to and thoughts on the typing of ovarian carcinomas
}

\author{
W G McCluggage
}

Correspondence to:

Professor W Glenn McCluggage, Department of Pathology, Royal Group of Hospitals Trust, Grosvenor Road, Belfast BT12 6BL, Northern Ireland, UK; glenn. mccluggage@belfasttrust.hscni. net

Accepted 26 July 2007 Published Online First 17 August 2007

\section{ABSTRACT}

Ovarian carcinomas of epithelial type comprise a heterogeneous group of neoplasms, each with a different underlying pathogenesis and natural behaviour. Accurate classification of ovarian carcinomas is important since each type may be associated with a different behaviour, natural history and outcome. Precise classification is also critical to determine whether alternative therapeutic strategies are appropriate for different tumour types. Previous studies have shown significant interobserver variation in the typing of ovarian carcinomas. There are several areas where there are particular difficulties; these include the distinction between high-grade serous and endometrioid adenocarcinomas and the distinction between a true clear cell carcinoma and clear cell areas within other adenocarcinomas. This review details my approach to the typing of ovarian carcinomas. Morphological assessment, which remains the mainstay in diagnosis, can be supplemented by immunohistochemistry which, for example, is useful in the distinction between serous carcinomas (WT1 positive) and other carcinomas (generally WT1 negative). In recent years, there has been emerging new information regarding the major underlying molecular events in several types of ovarian carcinoma. This has resulted in the acceptance that there are two distinct types of ovarian serous carcinoma. These are termed low-grade and high-grade serous carcinoma, but represent two distinct tumour types rather than low-grade and high-grade variants of the same neoplasm. The integration of clinical, morphological and molecular data has resulted in a more precise classification of ovarian carcinomas and has resulted in the proposal for a broad dualistic pathway of ovarian epithelial carcinogenesis with, in general, low-grade type 1 tumours evolving from benign and borderline neoplasms through a well-defined adenoma-carcinoma sequence, and high-grade type 2 neoplasms arising from an, as yet, undefined precursor lesion.

Ovarian carcinomas of epithelial type comprise a heterogeneous group of neoplasms. The major types of primary ovarian epithelial malignancy ${ }^{1}$ are listed in the box. Each tumour type has a different underlying pathogenesis and natural behaviour. Although, currently, management of ovarian carcinoma is largely dependent on factors such as tumour grade and stage, and not usually on cell type, it is important to accurately type ovarian carcinomas to ascertain whether the various neoplasms have a different behaviour independent of stage and other clinicopathological parameters. Typing is also important since some tumours, such as mucinous and clear cell carcinoma, seem to exhibit a poor response to platinum-based chemotherapy. ${ }^{2}$ In fact, tumour type may be a more reliable predictor of response to chemotherapy than tumour grade. ${ }^{2}$ This review details my thoughts on and approach to the typing of ovarian carcinomas and is meant as a guide to the practising surgical pathologist. Morphology remains the mainstay in diagnosis but immunohistochemistry may be of value as a supplement in problematic cases. Although this review is not primarily concerned with tumour grading, comments will be made regarding this, where appropriate. The pathogenesis of ovarian carcinoma is largely unknown because of the lack of a tumour progression model. However, in recent years, significant new data have emerged regarding major underlying molecular events in ovarian carcinomas. This is discussed and, when integrated with clinical and morphological data, has resulted in a proposal for two broad categories of ovarian epithelial malignancy. ${ }^{3}$

\section{RELATIVE FREOUENCY OF OVARIAN CARCINOMAS}

Serous adenocarcinoma is the most common primary ovarian epithelial malignancy. Traditionally, mucinous carcinoma has been regarded as the second most common type followed by endometrioid and clear cell carcinoma. ${ }^{4}$ A recent study from the Washington area of consecutive cases of ovarian carcinoma operated upon in a single large hospital (the study excluded consultation cases and included ovarian carcinosarcomas and primary peritoneal carcinomas, essentially all of which have an epithelial component of serous type) showed a different frequency of the various types of ovarian carcinoma ${ }^{5}$ which would be in broad agreement with my own experience

In that study, ${ }^{5} 68 \%$ of ovarian carcinomas were serous in type. The second most common was clear cell $(13 \%)$, followed by endometrioid and mucinous ( $9 \%$ and $3 \%$, respectively). Six per cent of tumours were of mixed type and only $1 \%$ were transitional carcinomas. If primary peritoneal serous carcinomas, carcinosarcomas and mixed tumours with a serous component were combined with the serous tumours, then serous carcinomas comprised $78 \%$ of all cases and $87 \%$ of advanced stage (stage III and IV) cases. It was concluded that a significant majority of ovarian carcinomas, especially of advanced stage, are of serous type. The main differences from previous studies were an increase in the percentage of serous carcinomas, a marked decrease in the proportion of mucinous carcinomas, and a reversal of the endometrioid and clear cell ratio. However, other studies have found a greater percentage of endometrioid carcinomas. ${ }^{6}$ This is likely to be a reflection of the fact that 
Major types of primary ovarian epithelial malignancy

- Serous adenocarcinoma

- Mucinous adenocarcinoma

- Endometrioid adenocarcinoma

- Clear cell carcinoma

- Transitional carcinoma

- Squamous carcinoma

- Undifferentiated carcinoma

- Mixed carcinoma

distinction between high-grade serous and endometrioid carcinomas is poorly reproducible (discussed below).

The underlying reasons behind the marked decline in ovarian mucinous carcinomas are well known. In older studies, it is likely that many presumed primary ovarian mucinous carcinomas, especially of advanced stage, were secondaries. Given the improved appreciation of the morphological features of metastatic mucinous adenocarcinoma in the ovary, ${ }^{7-9}$ including the well-known maturation phenomenon resulting in areas resembling benign and borderline mucinous cystadenoma, and the use of differential cytokeratin staining, ${ }^{10-13}$ pathologists are now much better at identifying metastatic mucinous carcinomas, although problems still exist. It is now also clear that ovarian mucinous carcinomas and so-called borderline neoplasms associated with pseudomyxoma peritonei are almost invariably of appendiceal origin, ${ }^{14-16}$ with the rare exception of primary ovarian intestinal-type mucinous neoplasms arising in a dermoid cyst. There has also been a redefinition of the criteria for diagnosis of a mucinous carcinoma with expansile or nondestructive invasion and the distinction of this from a mucinous borderline tumour at the upper end of the spectrum with intraepithelial carcinoma. ${ }^{17}$ Primary ovarian mucinous carcinomas, although they occur, are relatively rare and advanced stage primary ovarian mucinous carcinomas are extremely uncommon. ${ }^{5}$ In this scenario, a secondary should always be strongly considered. The different incidence of primary ovarian mucinous carcinomas in various institutions is likely to be due to differing criteria employed in the distinction between a borderline mucinous tumour with intraepithelial carcinoma and a well-differentiated mucinous adenocarcinoma exhibiting expansile invasion.

\section{REPRODUCIBILITY OF HISTOLOGICAL TYPING OF OVARIAN CARCINOMAS}

Several studies have examined the reproducibility of histological typing of ovarian carcinomas and all illustrate, not unexpectedly, that interobserver agreement is less than perfect. ${ }^{18-23}$ For example, Brugghe et al found total agreement among observers in only $61 \%$ of cases. ${ }^{18}$ Another study found that agreement was better for mucinous and clear cell carcinomas than endometrioid and serous neoplasms, and was no better amongst pathologists trained in gynaecological pathology than those with no specific interest. ${ }^{19}$ Other studies have found that histologic typing of ovarian cancers is less consistent than grading. ${ }^{20}$ Although these studies do not reflect everyday practice in that only a single slide is examined and there is no information regarding clinical or gross features and no advent to revert to immunohistochemistry, they do suggest real difficulties.

From personal experience, typing is reproducible for welldifferentiated tumours of the four most common types, namely serous, endometrioid, clear cell and mucinous (as discussed, there is significant variability amongst pathologists as to what constitutes invasion in ovarian mucinous neoplasms, but typing a tumour as mucinous is generally not problematic). However, there are significant problems with regard to typing poorly differentiated carcinomas. Many of the difficulties relate to the categories of high-grade serous, high-grade endometrioid and undifferentiated carcinoma. This has also been noted in other studies $^{21}$ and was extensively discussed at the United States and Canadian Academy of Pathology meeting in San Diego, March 2007. This was also my experience in reviewing histological sections of advanced ovarian carcinomas for the ICON5 trial (personal unpublished observations). Another source of disagreement is the categorisation of clear cell areas within ovarian carcinomas, specifically whether these represent a clear cell carcinoma or component of clear cell carcinoma or clear cell areas within a high-grade serous, endometrioid or undifferentiated carcinoma. ${ }^{24}$ These difficulties are discussed in detail below.

\section{GENERAL REMARKS ON TYPING OF OVARIAN CARCINOMAS}

Traditional management of advanced-stage ovarian carcinoma is surgical debulking followed by adjuvant chemotherapy. There is now an increasing tendency to administer upfront chemotherapy for advanced ovarian carcinoma, especially with miliary disease, once the diagnosis is firmly established and this may or may not be followed by surgery. There are ongoing trials, for example the CHORUS (Chemotherapy or Upfront Surgery) trial in the UK, investigating the relative merits of surgery followed by chemotherapy versus chemotherapy followed by surgery. The morphological features of ovarian carcinomas treated by chemotherapy often differ markedly from native tumour. Many ovarian carcinomas post-chemotherapy have abundant clear or eosinophilic cytoplasm (fig 1) and the nuclear features are often bizarre. ${ }^{25}$ It may be difficult to identify residual tumour cells due to pronounced chemotherapy effect with marked fibrosis, necrosis, inflammation, cholesterol cleft formation, haemosiderin deposition and dystrophic calcification. Unless there is no or minimal response, ovarian carcinomas can, in general, not be reliably typed following chemotherapy and there is a tendency to misdiagnose tumours as clear cell carcinomas due to the abundant clear cytoplasm. If upfront chemotherapy is being administered, I would recommend a prechemotherapy tissue biopsy (usually a radiologically guided biopsy of the omental cake) for definitive typing, rather than relying on cytology of the ascitic fluid. An algorithm demonstrating my approach to the typing of ovarian carcinomas is presented in fig 2. In the following sections, each of the major types of ovarian carcinoma is discussed in turn.

\section{OVARIAN SEROUS CARCINOMA}

As discussed, serous carcinoma is by far the most common ovarian epithelial malignancy. Most tumours are advanced (ie, stage III or IV) at diagnosis. Serous carcinoma, like other ovarian carcinomas, is traditionally graded as 1,2 or 3 (well, moderately or poorly differentiated). Several grading systems are in use ${ }^{26-28}$ and, in general, there is inconsistency between laboratories and even within laboratories in the grading of ovarian carcinomas. There are also problems in typing high-grade carcinomas. Most, although not all, serous carcinomas form glands and have a papillary architecture, at least focally, and many contain psammoma bodies. However, solid variants occur with little or no papillary or glandular differentiation. These solid tumours merge with undifferentiated carcinoma and the morphological 

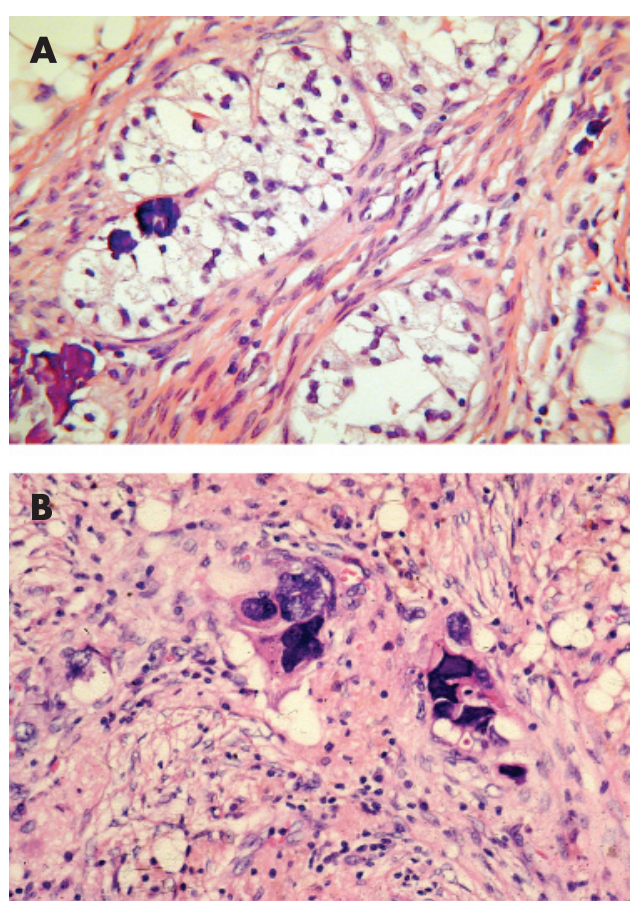

Figure 1 Ovarian carcinoma resected following chemotherapy treatment. (A) The residual tumour cells have abundant clear cytoplasm. (B) Tumour cells with bizarre nuclei are present in an abundant fibrotic and inflamed stroma.

features overlap with high-grade endometrioid carcinoma; as such there is significant interobserver variability in distinguishing between these neoplasms. ${ }^{21}$ The World Health Organization definition of an undifferentiated carcinoma is one showing no differentiation or only very small foci of differentiation ${ }^{1}$ and, in my opinion, this diagnosis should be given for neoplasms exhibiting these features. Undifferentiated carcinoma does not include small cell and large cell neuroendocrine carcinoma and, if necessary, these should be excluded by appropriate immunohistochemistry. However, I make the point that CD56 is not a specific neuroendocrine marker and a significant percentage of undifferentiated and high-grade serous carcinomas are positive. ${ }^{29}$ Features favouring a poorly differentiated serous rather than a poorly differentiated endometrioid adenocarcinoma include the presence of psammoma bodies, slit-like as opposed to round glandular spaces, tumour giant cells with bizarre nuclei, smaller, more complex papillae, and a greater degree of cellular budding (fig 3, table 1). Features in favour of a poorly differentiated endometrioid adenocarcinoma are round, punched-out rather than slit-like spaces, longer broader papillae, and one or more of the triad of squamous elements, an adenofibromatous growth pattern or endometriosis. However, none of these features is pathognomonic and, as discussed, there is significant interobserver variability in distinguishing between these two tumour types. Generous sampling and the examination of many sections may reveal better differentiated areas and these may be found in the extraovarian deposits. Some pathologists tend to diagnose poorly differentiated ovarian carcinomas as serous in type, while others classify them as endometrioid or mixed serous and endometrioid. My personal opinion is that the majority of these are serous neoplasms. In this distinction, WT1 immunohistochemical staining may be of value. ${ }^{30-33}$ Most primary ovarian (as well as primary peritoneal and tubal) serous carcinomas exhibit diffuse nuclear positivity with WT1, while most endometrioid adenocarcinomas are negative or focally positive. p53 may also be of value in that most ovarian serous carcinomas (OSCs) are diffusely positive

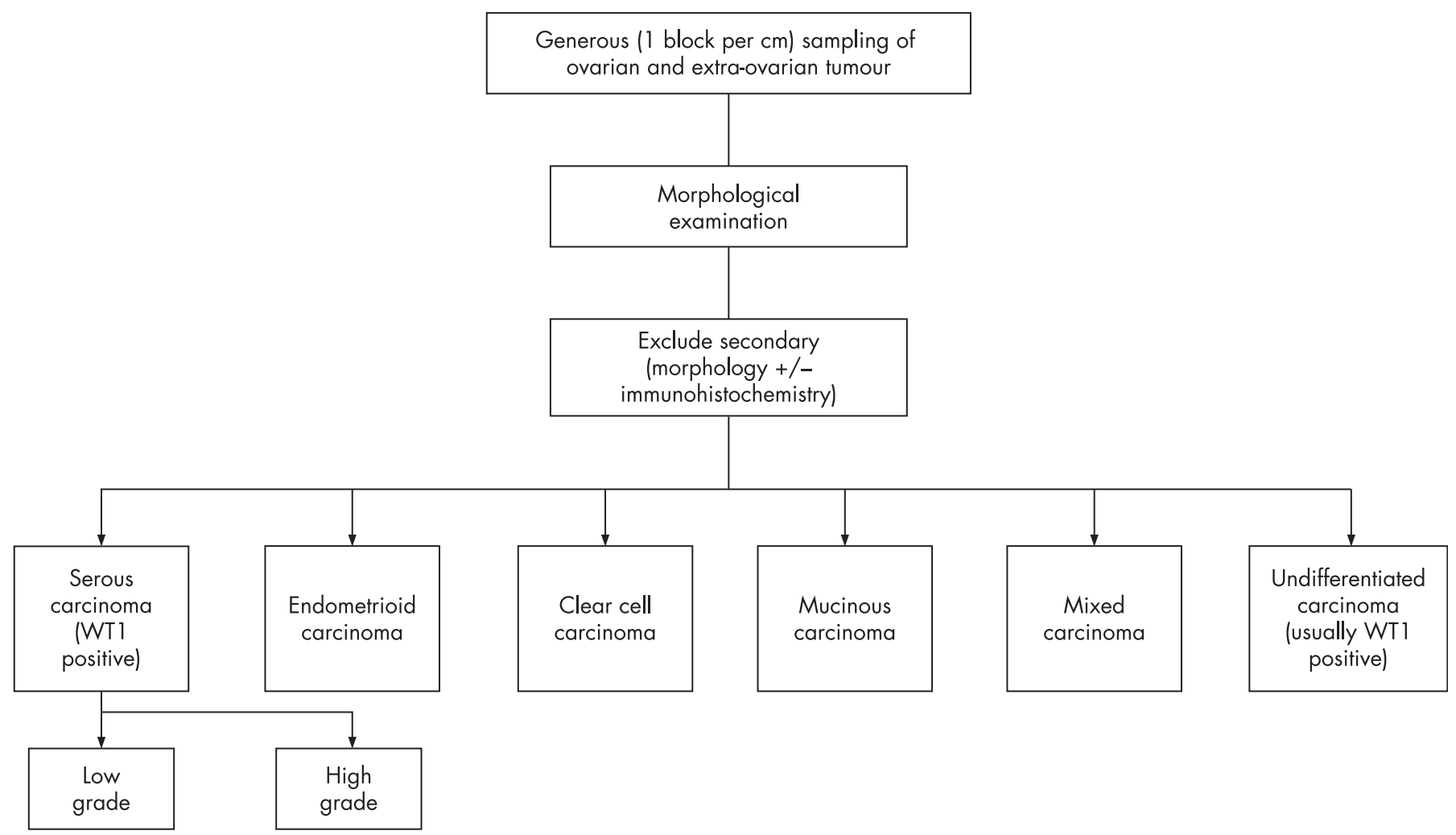

Figure 2 Algorithm for typing ovarian carcinoma. 
while most endometrioid adenocarcinomas are negative, although some high-grade endometrioid neoplasms are positive. p16 (p16INK4A), a cyclin-dependent kinase IV inhibitor which is integral to $\mathrm{pRb}$-mediated control of the G1-S phase transition of the cell cycle, is more likely to be diffusely and strongly positive in serous than in endometrioid adenocarcinomas. ${ }^{34} 35$ Vimentin and nuclear $\beta$-catenin positivity favours an endometrioid adenocarcinoma, although not all cases are positive. In problematic cases, I would recommend WT1 immunohistochemical staining as an adjunct to help distinguish between a high-grade serous and a high-grade endometrioid adenocarcinoma. Most high-grade serous carcinomas and neoplasms, which some classify as high-grade endometrioid adenocarcinoma, are not separable on the basis of gene expression profiling or molecular events, ${ }^{36}$ suggesting that these are the same tumour and, I feel, most should be classified as high-grade serous. The distinction between a true clear cell carcinoma and a serous carcinoma with clear cells is discussed below.

\section{TWO TYPES OF OSC}

Recent studies, mainly emanating from the Baltimore group of Robert J Kurman, have convincingly demonstrated that there are two distinct types of OSC. ${ }^{37-42}$ Although termed low-grade and high-grade OSC, it is important to emphasise that these are not two grades of the same neoplasm, but rather two distinct tumour types with different underlying pathogenesis, molecular events, behaviour and prognosis. High-grade OSC is much more common than low-grade. The postulated pathways leading to the development of low-grade and high-grade OSC are shown in fig 4. Low-grade OSC is thought to arise in a stepwise fashion from a benign cystadenoma through a borderline cystadenoma through a borderline cystadenoma with a micropapillary pattern to an invasive low-grade OSC. Thus, there is a welldefined adenoma-carcinoma sequence. However, I make the point that it is relatively rare to see areas of invasive low-grade OSC in a serous borderline cystadenoma and conversely in most invasive low-grade OSC a borderline component is not seen. Therefore, it is not proven that all low-grade OSC arise from a pre-existing borderline tumour, and it is possible that some or many do not. In contrast, high-grade OSC is thought to arise directly from the ovarian surface epithelium or the epithelium of cortical inclusion cysts with, as yet, no well-defined precursor lesion; the precursor lesion has been speculated to be ovarian intraepithelial neoplasia, ${ }^{43}$ which is severe atypia involving the surface epithelium or the epithelium of cortical inclusion cysts. There is now emerging evidence (not discussed in this review) that many high-grade OSC may actually be derived from the epithelium of the distal fimbrial portion of the fallopian tube. ${ }^{44}$

${ }^{47}$ Low-grade and high-grade OSC are both typically high stage at presentation. However, low-grade OSC is an indolent, slowgrowing neoplasm with a poor response to platinum-based chemotherapy. Although usually resulting in death of the patient, low-grade OSC may be compatible with prolonged survival. In contrast, high-grade OSC is a highly aggressive tumour which, while responding well initially to platinumbased therapy in most cases, typically recurs and is usually eventually fatal. The distinction between low- and high-grade OSC is based on morphology (fig 5). ${ }^{48}$ In low-grade OSC (also termed invasive micropapillary serous carcinoma by some investigators - a term I would not recommend since some low-grade OSC do not have a micropapillary architecture, and conversely many high-grade OSC have a micropapillary growth pattern), the nuclei are uniform with only mild atypia and $\leqslant 12$ mitoses per 10 high power fields (the mitotic count is usually approximately two per 10 high-power fields). There is no necrosis or multinucleate tumour cells. High-grade OSC exhibits moderate to marked nuclear atypia and greater than 12 mitoses per 10 high-power fields. Necrosis and multinucleate tumour cells are often present. The distinction between highgrade and low-grade OSC has been shown to be reproducible. ${ }^{49}$ Psammoma bodies are common in high-grade and low-grade OSC. Psammocarcinoma is a term that is used for a tumour
Figure 3 High-grade serous carcinoma with slit-like glandular spaces $(A)$ and bizarre tumour giant cells (B). The tumour exhibits diffuse nuclear WT1 positivity (C). In contrast, a high-grade endometrioid carcinoma contains round, punched-out glandular spaces (D).
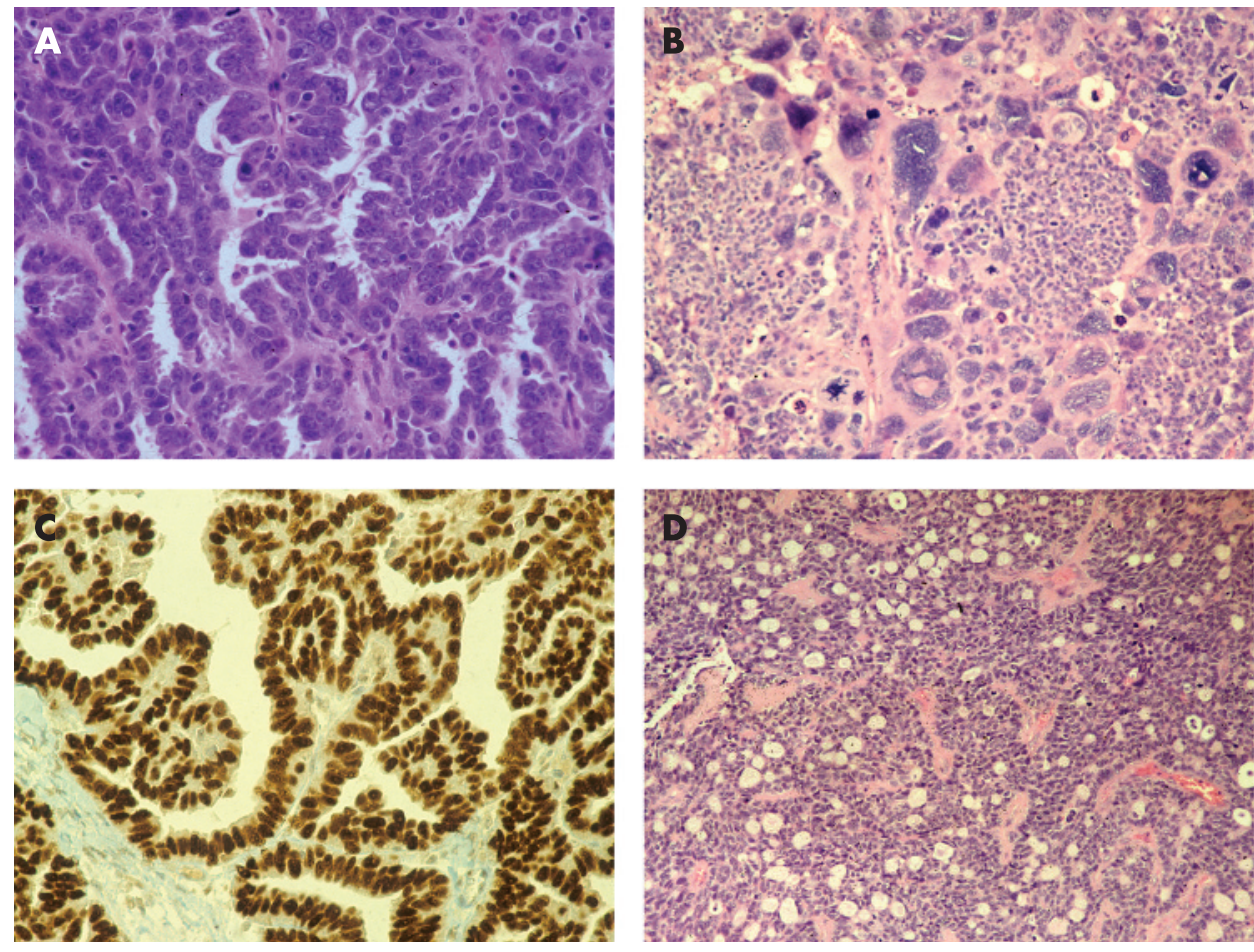
Table 1 Distinction between poorly differential serous and poorly differentiated endometrioid adenocarcinoma

\begin{tabular}{|c|c|c|}
\hline Morphology & Serous & Endometrioid \\
\hline Glandular spaces & Slit-like & Round, punched-out \\
\hline Psammoma bodies & Common & Rare \\
\hline Tumour giant cells & Common & Rare \\
\hline Papillae & $\begin{array}{l}\text { Small, complex with } \\
\text { budding }\end{array}$ & Longer and broader \\
\hline Adenofibromatous growth pattern & Rare & Common \\
\hline Squamous elements & Rare & Common \\
\hline Endometriosis & Rare & Common \\
\hline \multicolumn{3}{|l|}{ Immunohistochemistry } \\
\hline WT1 & Diffuse positive & $\begin{array}{l}\text { Negative or focally } \\
\text { positive }\end{array}$ \\
\hline p53 & Diffuse positive & $\begin{array}{l}\text { Negative, focally or } \\
\text { diffuse positive }\end{array}$ \\
\hline p16 & Diffuse positive & $\begin{array}{l}\text { Negative or focally } \\
\text { positive }\end{array}$ \\
\hline Vimentin & Negative & Sometimes positive \\
\hline$\beta$-Catenin & Membranous staining & $\begin{array}{l}\text { Membranous and, in } \\
\text { some cases, nuclear } \\
\text { positivity }\end{array}$ \\
\hline
\end{tabular}

with extensive psammoma body formation, and is usually a form of low-grade serous carcinoma. ${ }^{50}$ Since otherwise the morphology is identical to a low-grade serous carcinoma, I do not believe it should be split from this group of neoplasms.

Underlying molecular events differ between low-grade and high-grade OSC. ${ }^{3}$ Low-grade OSC is associated with $\mathrm{k}$-ras or braf mutation in approximately two-thirds of cases. ${ }^{39} 4142$ These mutations occur early in the evolution of low-grade OSC since they are also found in borderline and benign areas within the same tumour. ${ }^{41} \mathrm{k}$-ras and b-raf mutations are mutually exclusive (ie, one but not both may be found in a particular neoplasm). Low-grade OSC is not associated with p53 mutations. ${ }^{40}$ In contrast, high-grade OSC contains, in most cases, a p53 mutation that occurs early in the development of the tumour ${ }^{40}$; they are not associated with k-ras or b-raf mutation but have high chromosomal instability. I would recommend that, instead of grading OSCs using a three-tiered system, they are divided into high-grade and low-grade neoplasms. High-grade OSC exhibits significantly higher expression of p53, MIB1, bcl-2, ckit, Her-2 neu and p16 than low-grade OSC. ${ }^{34} 51$ Both neoplasms express WT1 at high levels. ${ }^{51}$ Although two distinct tumour types, it is probable that, on rare occasions, a low-grade OSC may transform into a high-grade neoplasm, or a high-grade OSC may arise directly from a serous borderline tumour. ${ }^{52}$ Currently, management of low-grade and high-grade OSC is identical. However, low-grade OSC responds poorly to platinum-based therapy and since most of these neoplasms exhibit positive immunohistochemical staining with oestrogen receptor (ER), there is a school of thought that hormonal manipulation may play a role in management. However, there is no evidence base for this and clearly this is something which needs to be further investigated.

\section{MUCINOUS CARCINOMAS}

As discussed, primary ovarian mucinous carcinomas are relatively rare. In the previously referred to study of Seidman et al, only six of 220 ovarian carcinomas were mucinous in type and only one was of advanced stage. ${ }^{5}$ The main problems relating to the diagnosis of a primary ovarian mucinous carcinoma are twofold. First is the exclusion of a secondary adenocarcinoma, and second is the distinction between a borderline tumour at the upper end of the spectrum with intraepithelial carcinoma and an invasive adenocarcinoma. Invasion in ovarian mucinous adenocarcinomas can be either expansile (non-destructive or confluent glandular) or infiltrative (destructive) in type. ${ }^{17}$ It may be difficult to diagnose a mucinous carcinoma with expansile invasion due to the orderly growth pattern and absence of a stromal reaction. My criteria for the distinction between a borderline mucinous tumour with intraepithelial carcinoma and a carcinoma exhibiting expansile invasion are that the latter contain closely packed small- to intermediate-sized glands with a confluent back-to-back arrangement and no or minimal intervening stroma. A labyrinthine or cribriform growth pattern is also common and the epithelium should be cytologically malignant. The expansile area should exceed $5 \mathrm{~mm}$ in at least one dimension; a dimension less than this qualifies for a diagnosis of microinvasive carcinoma. Establishing a diagnosis of a mucinous carcinoma with infitrative stromal invasion is straightforward but a secondary neoplasm should always be considered. It is stressed that primary ovarian mucinous tumours may be extremely heterogeneous within an individual neoplasm. It is not uncommon to see benign, borderline, borderline with intraepithelial carcinoma and malignant areas side by side within the

Figure 4 Developmental pathways of low-grade and high-grade serous carcinoma. OSC, ovarian serous carcinoma.

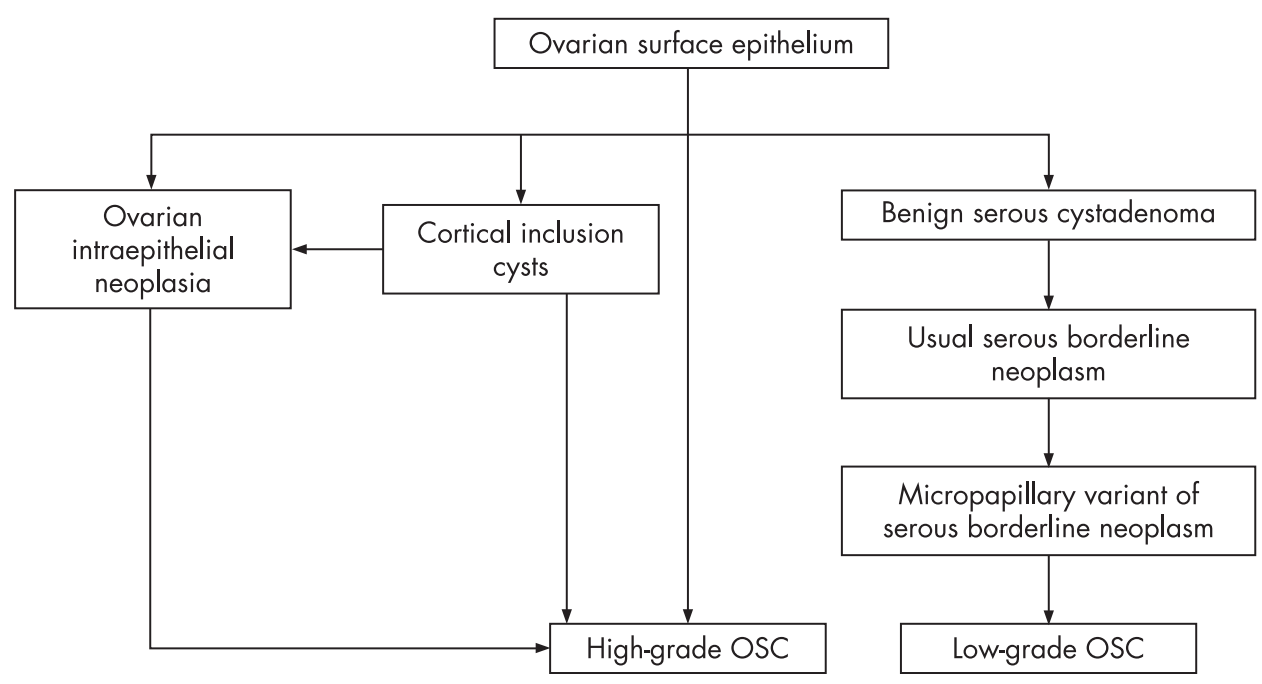



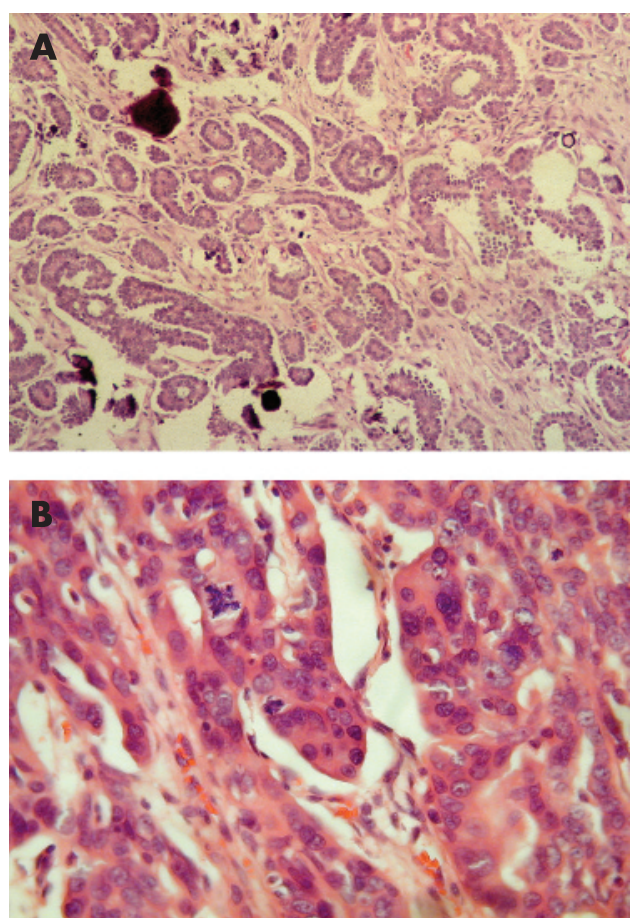

Figure 5 (A) Low-grade serous carcinoma with micropapillary architecture, mild nuclear atypia and few mitoses. (B) In contrast, a highgrade serous carcinoma exhibits marked nuclear atypia and contains many mitotic figures.

same neoplasm (fig 6). Thorough pathological sampling is mandatory in such cases. Areas which are solid or different in appearance should be preferentially sampled and if there are worrisome features in the initial sections, such as intraepithelial carcinoma or areas suspicious of invasion or microinvasion, additional sections should be examined. ${ }^{53}$

There are two distinct types of primary ovarian mucinous adenocarcinoma and mucinous borderline tumour. These are the much more common intestinal type and the rare endocervical or Müllerian type. ${ }^{54} 55$ The presence of goblet cells is not a prerequisite for an intestinal type mucinous tumour, and many of these exhibit gastric or pancreaticobiliary differentiation. ${ }^{56}$ In fact, many of the intestinal type carcinomas do not exhibit obvious enteric differentiation and in practice these are often simply designated mucinous carcinoma of non-specific type. These differ from the very rare endocervical type mucinous carcinoma which should be specifically separated from the intestinal or non-specific type. The overall architecture of endocervical-type mucinous neoplasms (borderline tumours are more common than carcinomas, but are much less common than intestinal type borderline neoplasms) resembles those of the corresponding serous tumour. Endocervical-type mucinous adenocarcinomas are extremely uncommon and may be associated with a borderline mucinous tumour of endocervical type or a seromucinous borderline tumour. ${ }^{54}$ There is also an association with endometriosis. In the distinction between an intestinal or non-specific and an endocervical-type ovarian mucinous tumour, immunohistochemistry may be of value (table 2). ${ }^{57-60}$ Both are typically diffusely positive with CK7, although intestinal type neoplasms may be only focally positive or even negative on rare occasions. Intestinal type mucinous ovarian tumours typically express, either focally or diffusely, enteric markers such as CK20, CDX2, CEA, villin and CA19.9 ${ }^{57-60}$; endocervical type mucinous neoplasms are usually negative with these markers. In contrast, endocervical type tumours usually express Müllerian markers, such as CA125, ER and progesterone receptor (PR), which are negative in intestinal type neoplasms. Rare intestinal type neoplasms are of teratomatous origin and arise in dermoid cysts. ${ }^{61}$

There has been little study of the molecular events in endocervical-type ovarian mucinous neoplasms; given the close morphological relationship with serous borderline tumours, similar molecular events might be anticipated, but this has not been investigated. Intestinal-type mucinous carcinomas, like low-grade OSC, are thought to arise through a well-defined adenoma-carcinoma sequence (fig 7) from a benign cystadenoma through a borderline cystadenoma, through a borderline cystadenoma with intraepithelial carcinoma, to a mucinous carcinoma. The main criterion for intraepithelial carcinoma in a borderline tumour is severe nuclear atypia. ${ }^{53}$ A category of microinvasion is also recognised $d^{53}$; there is no universally agreed upper size limit for microinvasion, but most use $5 \mathrm{~mm}$ (some use $3 \mathrm{~mm}$ or $10 \mathrm{~mm}^{2}$ ). It has been suggested that microinvasion in mucinous borderline tumours should be classified as borderline tumour with microinvasion or borderline tumour with microinvasive carcinoma. ${ }^{53}$ Although the morphological features are not well characterised, and any clinically significant difference between these two categories is not established, I feel they should be distinguished for future studies to determine if their behaviour differs. In borderline tumour with microinvasion, the borderline component from which the focus of microinvasion arises does not exhibit intraepithelial carcinoma; the cytological features of the microinvasive focus are low grade and similar to those in the adjacent borderline tumour. In borderline tumour with microinvasive carcinoma, the borderline component exhibits intraepithelial carcinoma, and the cytological features of the microinvasive focus are typically high grade; this equates to a small carcinoma. Mucinous ovarian tumours of intestinal type commonly exhibit k-ras mutations, and identical mutations have been demonstrated in benign, borderline and malignant areas within the same neoplasm, suggesting that $\mathrm{k}$ ras mutation is an early event in the evolution. ${ }^{62-65}$ Mutations of b-raf have not been found in ovarian mucinous neoplasms of intestinal type.

\section{ENDOMETRIOID ADENOCARCINOMA}

Most ovarian endometrioid adenocarcinomas are low grade and low stage. They often, although not always, arise from endometriosis and/or a pre-existing benign or borderline adenofibroma $^{66}{ }^{67}$; there is a closer association between ovarian clear cell carcinoma and endometriosis than is the case with endometrioid adenocarcinoma. Typing of a low-grade endometrioid adenocarcinoma is usually straightforward, although problems arise in the distinction between a grade 1 endometrioid adenocarcinoma and a borderline endometrioid adenofibroma. ${ }^{68}$ Some grade 1 endometrioid adenocarcinomas exhibit obvious stromal invasion, while in others the diagnosis is made on the basis of a back-to-back glandular architecture with exclusion of stroma. ${ }^{68}$ The presence of one or more of the triad of adenofibromatous areas, squamous elements and endometriosis may be a useful pointer to the diagnosis of an endometrioid neoplasm. Unusual morphological patterns seen in ovarian endometrioid adenocarcinomas, either focally or diffusely, include sex cord-like formations and spindle cell

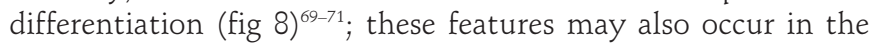
corresponding uterine neoplasms. ${ }^{72}$ The other morphological variants of uterine endometrioid adenocarcinoma, such as secretory and oxyphilic, may also occur in the ovary. High-grade 

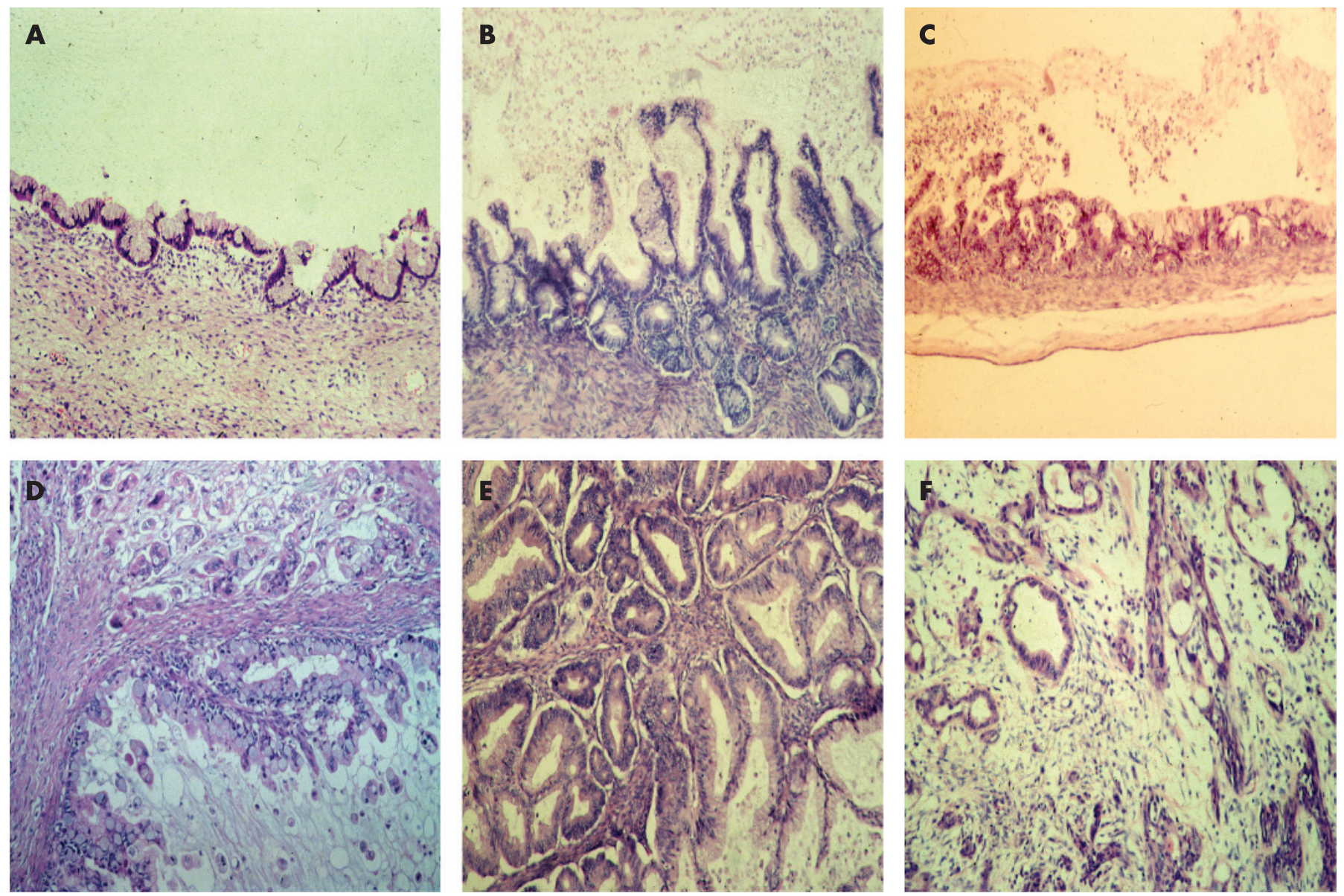

Figure 6 Areas within the same ovarian mucinous tumour of benign cystadenoma (A), borderline cystadenoma (B), borderline cystadenoma with intraepithelial carcinoma (C), borderline tumour with microinvasion (D), and adenocarcinoma exhibiting expansile (E) and infiltrative invasion (F).

ovarian endometrioid adenocarcinomas exist but, in my opinion, are rare. The distinction between a high-grade endometrioid and a high-grade serous adenocarcinoma has been discussed earlier. Vimentin and nuclear $\beta$-catenin immunoreactivity are in favour of an endometrioid rather than a serous adenocarcinoma.

Metastatic adenocarcinomas from diverse sites including the colorectum, cervix, biliary tree and stomach may mimic a primary ovarian endometrioid adenocarcinoma. ${ }^{9} 107374$ Careful morphological examination combined, if necessary, with immunohistochemistry, facilitates the distinction. Differential cytokeratin (CK7 and CK20) staining is especially useful in the distinction from a metastatic colorectal adenocarcinoma (table 3) ${ }^{11-13}$ Other markers which may assist in this distinction include ER, CA125, CEA and CDX2. ${ }^{75-78}$ The latter is an enteric

Table 2 Typical immunophenotype of intestinal- and endocervical-type mucinous ovarian tumours

\begin{tabular}{lll}
\hline & Intestinal type & Endocervical type \\
\hline CK7 & Diffuse or focal positive & Diffuse positive \\
CK20 & Negative, focal or diffuse positive & Negative \\
CEA & Often positive & Negative \\
CA19.9 & Often positive & Negative \\
CDX2 & Often positive & Negative \\
Villin & Often positive & Negative \\
ER/PR & Negative & Positive \\
CA125 & Negative & Positive \\
\hline
\end{tabular}

ER, oestrogen receptor; PR, progesterone receptor. marker which is diffusely positive in most colorectal adenocarcinomas, but which may also on occasions be positive in primary ovarian endometrioid carcinomas (personal observations). p16 may be of value in the distinction between a metastatic cervical adenocarcinoma (typically diffuse p16 positivity) and a primary ovarian endometrioid adenocarcinoma (typically p16 negative or

Mucinous cystadenoma

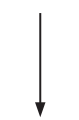

Borderline mucinous cystadenoma

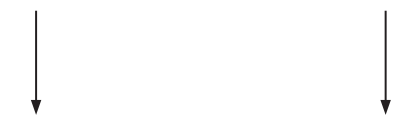

Borderline mucinous cystadenoma with intraepithelial carcinoma

Borderline tumour with microinvasion

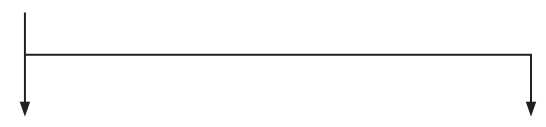

Mucinous carcinoma

Borderline tumour with microinvasive carcinoma

Figure 7 Developmental pathway of ovarian mucinous tumours of intestinal type. 
Figure 8 Low-grade endometrioid adenocarcinoma $(A)$ with areas of squamous differentiation (B). Some endometrioid adenocarcinomas exhibit a sex cord-like pattern (C) or areas of spindle cell differentiation (D).
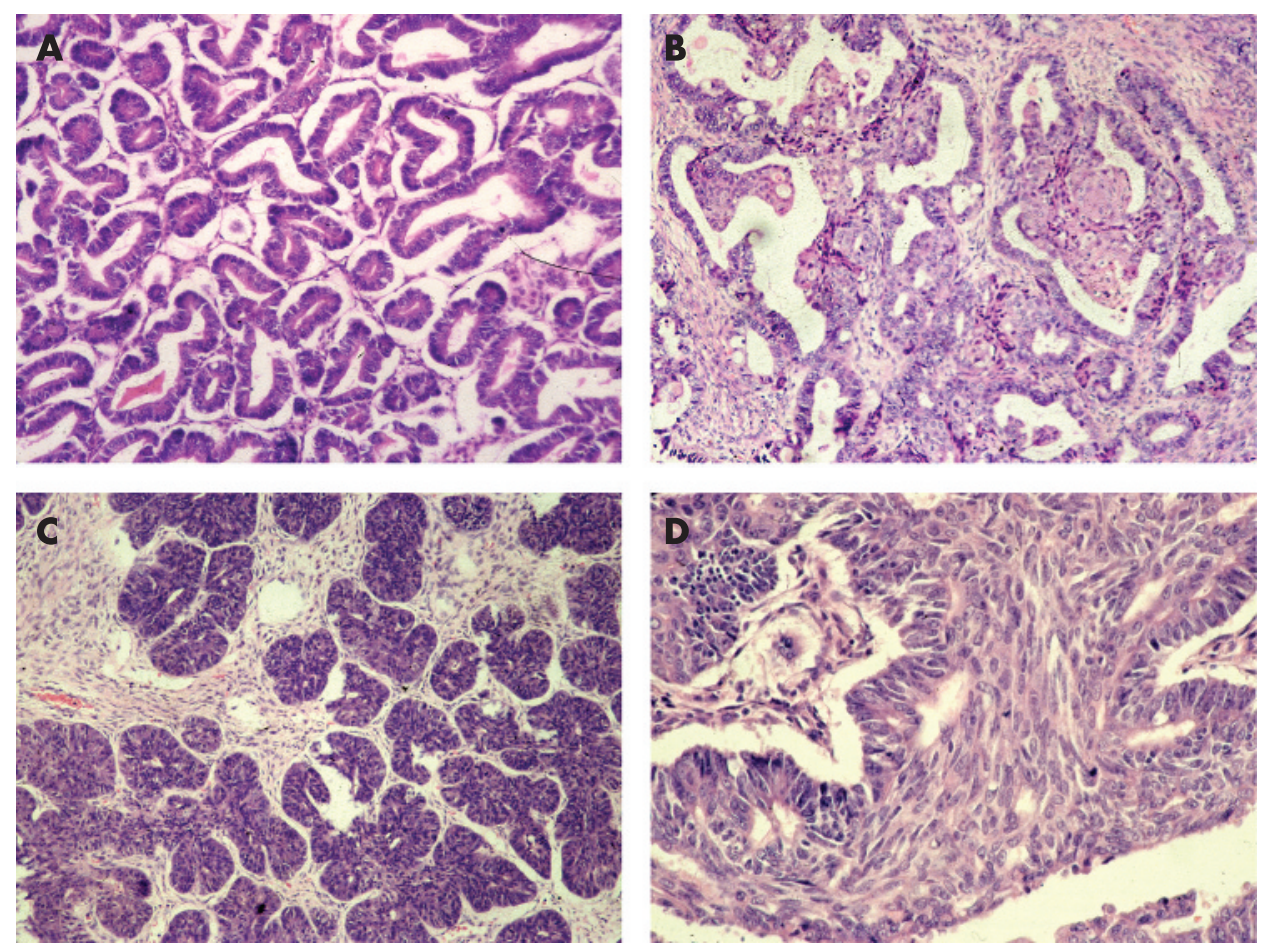

focally positive). ${ }^{35}$ Although some employ universal grading systems, such as the Silverberg system, ${ }^{2}$ for grading ovarian endometrioid adenocarcinomas, my own preference is to grade these neoplasms using the International Federation of Gynecology and Obstetrics grading system for uterine endometrioid adenocarcinomas. Endometrioid adenocarcinomas of the ovary exhibit similar molecular events to those occurring in uterine endometrioid adenocarcinomas (ie, PTEN, $\beta$-catenin and k-ras mutations and microsatellite instability). ${ }^{62} 79$

\section{CLEAR CELL CARCINOMA}

Most ovarian clear cell carcinomas arise from endometriosis. ${ }^{80}$ In my experience, careful sampling, especially concentrating on grossly cystic areas, will usually identify foci of definite or presumptive endometriosis, either in the same or contralateral ovary. I regard clear cell carcinomas as high-grade (grade 3) neoplasms. Since clear cell carcinomas not uncommonly contain few mitoses and may be cytologically and architecturally well differentiated, formal grading systems may result in these being assigned as grade 1 or 2 (as stated, I consider these grade 3 neoplasms). Clear cell carcinomas are characteristically composed of cells with abundant clear cytoplasm, often with prominent cell membranes, although an oxyphilic variant exists.

Table 3 Typical immunophenotype of primary ovarian endometrioid adenocarcinoma and metastatic colorectal adenocarcinoma

\begin{tabular}{lll}
\hline & $\begin{array}{l}\text { Ovarian endometrioid } \\
\text { adenocarcinoma }\end{array}$ & $\begin{array}{l}\text { Metastatic colorectal } \\
\text { adenocarcinoma }\end{array}$ \\
\hline CK7 & Positive & Negative \\
CK20 & Negative & Positive \\
CA125 & Positive & Negative \\
CEA & Negative & Positive \\
ER & Positive & Negative \\
CDX2 & Negative, focally or diffusely & Positive \\
& positive & \\
\hline
\end{tabular}

The latter is usually a focal finding within an otherwise typical clear cell carcinoma but occasionally is the predominant or exclusive element. Characteristically in clear cell carcinoma, an admixture of growth patterns is present, including solid, glandular, tubulocystic and papillary foci (fig 9). Hobnail cells and eosinophilic hyalinised stroma are common features. A plasmacytic infiltrate may be present. On occasions, a preexisting benign or borderline clear cell adenofibroma is identified. Most clear cell carcinomas are diagnosed without difficulty, but there is a tendency to overdiagnose clear cell carcinoma or a clear cell component within a mixed neoplasm due to the presence of clear cell areas within other types of ovarian carcinoma, especially serous and to a lesser extent endometrioid (fig 10). The presence of more typical areas of serous or endometrioid adenocarcinoma are useful pointers in diagnosis (as discussed later, sometimes a combination of clear cell and endometrioid adenocarcinoma occurs) and it is stressed that the mere presence of clear cells does not constitute a clear cell carcinoma. WT1 is usually negative in ovarian clear cell carcinoma, as is p53. Precursor lesions of ovarian clear cell carcinoma are not well described, but atypical clear cell change may be identified in the epithelium of endometriotic cysts adjacent to clear cell carcinoma. The molecular events underlying the development of ovarian clear cell carcinoma have not been extensively studied; this has been the subject of a recent review in this journal and will not be repeated. ${ }^{81}$

Rarely, renal clear cell carcinoma metastasises to the ovary, sometimes in the absence of a known primary. The morphological features usually differ markedly from ovarian clear cell carcinoma and diagnosis of a primary ovarian neoplasm is supported by the characteristic admixture of growth patterns and the presence of hobnail cells or endometriosis. A panel of immunostains, including CK7, CD10 and renal cell carcinoma marker, may assist. ${ }^{82}$ Renal cell carcinomas are typically CK7 negative and diffusely positive with $\mathrm{CD} 10$ and renal cell carcinoma marker. ${ }^{82}$ 
Figure 9 (A) Ovarian clear cell carcinoma with papillary architecture and eosinophilic hyaline stroma. Glandular (B) and solid (C) growth patterns are also common. (D) Hobnail cells are also a characteristic feature (D).
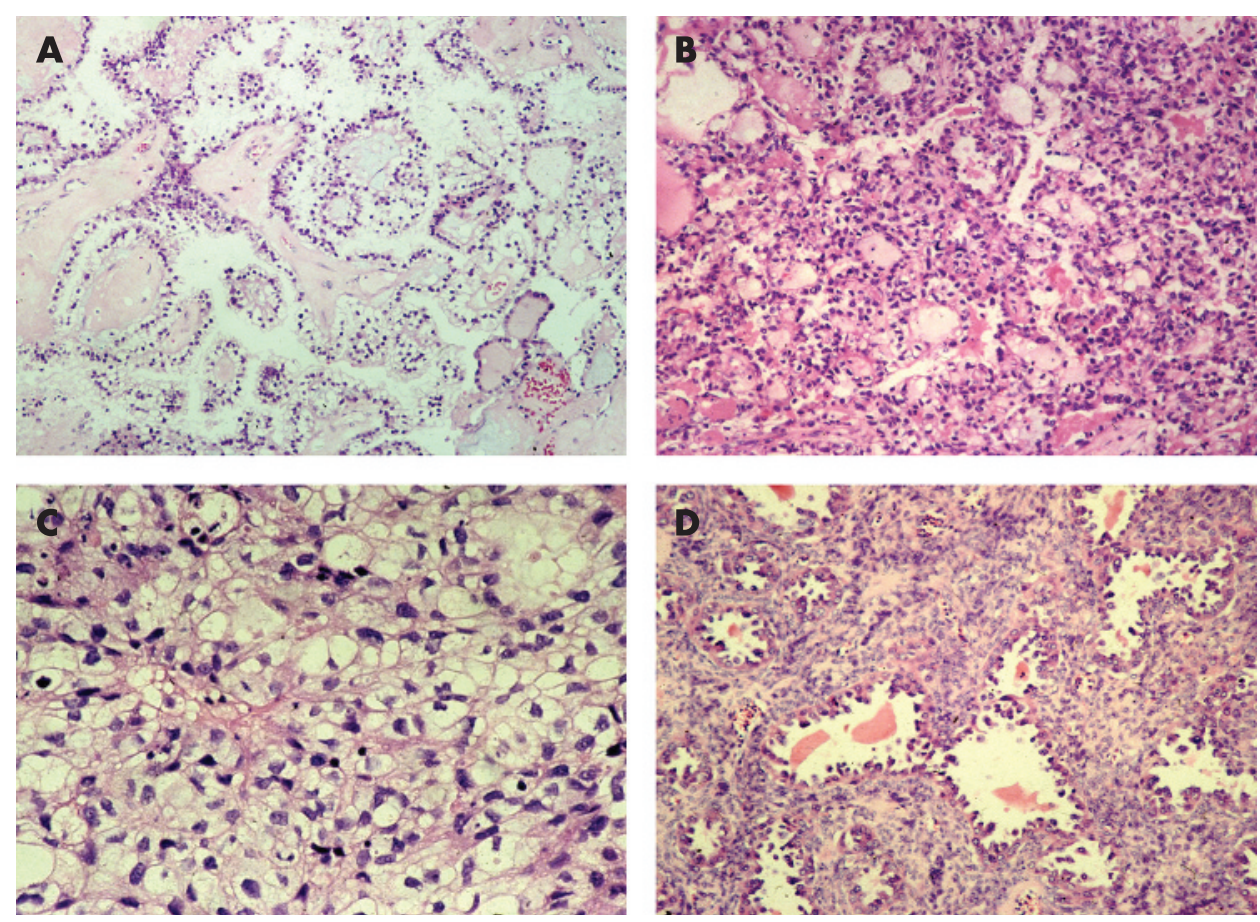

\section{TRANSITIONAL CARCINOMA}

In my opinion, primary ovarian transitional carcinomas are rare, although they do occur; however, some authorities make this diagnosis not uncommonly. ${ }^{83}$ I feel many cases which are diagnosed as transitional carcinoma probably represent variants of high-grade OSC and that transitional carcinoma is a poorly reproducible diagnosis. Other cases diagnosed as transitional
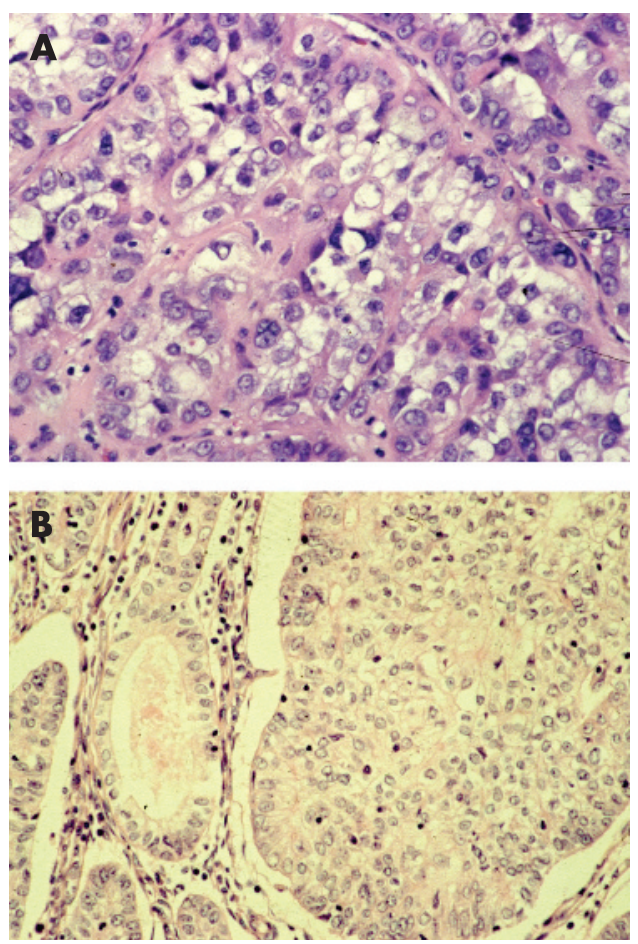

Figure 10 Ovarian serous $(A)$ and endometrioid $(B)$ adenocarcinoma with clear cells. (B) The clear cell change involves glandular and squamous elements. carcinoma may represent endometrioid adenocarcinomas with a transitional-like growth pattern. Morphological features commonly seen in ovarian transitional carcinomas include microspaces, large cystic spaces and large blunt papillae. ${ }^{83}$ Transitional carcinomas of the ovary express Müllerian and not urothelial markers $^{84}{ }^{85}$ (ie, they are variants of Müllerian tumour rather than exhibiting true urothelial differentiation). They are usually positive with WT1, ${ }^{86}$ a point in favour of many being variants of OSC. Some ovarian transitional carcinomas recur or metastasise as serous carcinomas, and this is further evidence that many are variants of the latter. When these neoplasms are well sampled, they often contain foci of classic serous or endometrioid adenocarcinoma. ${ }^{83}$ There is some weak evidence that transitional carcinomas may be more chemoresponsive than other primary ovarian carcinomas. ${ }^{27}$ There has been little or no study of the underlying molecular events in ovarian transitional carcinoma. I grade primary ovarian transitional carcinomas as for the corresponding urinary bladder tumours, although I reiterate that, in my experience, they are rare.

\section{MIXED TUMOURS}

The World Health Organization uses the 10\% rule (ie, the minor component should make up at least $10 \%$ of the neoplasm in order to qualify as a mixed tumour). ${ }^{1}$ However, I feel even if the minor component comprises $<10 \%$ it should be mentioned in the pathology report. In my experience, true mixed tumours of the ovary are relatively uncommon, although they do occur. A combination of endometrioid and clear cell carcinoma occurs since both tumours commonly arise within endometriosis. Cases which are diagnosed as mixed serous and endometrioid, or mixed serous and clear cell carcinoma, mostly, in my opinion, represent high-grade OSC with areas that mimic endometrioid or clear cell carcinoma; I feel a true combination of serous and endometrioid, or serous and clear cell carcinoma, is relatively uncommon. As discussed earlier. WT1 may be of value in distinguishing between serous (WT1-positive) and endometrioid and clear cell (WT1-negative) components. 


\section{PROPOSAL FOR TYPE 1 AND TYPE 2 OVARIAN CARCINOMA}

Given the major recent advances in our knowledge regarding underlying molecular events in the main types of ovarian epithelial malignancy, there has been a proposal by the Baltimore group for a broad dualistic pathway of ovarian epithelial carcinogenesis; similar to the uterus, the terms type 1 and type 2 ovarian carcinoma have been proposed. ${ }^{3}$ This does not imply that the terms type 1 and type 2 carcinoma should replace the specific histologic designations, or that all type 1 and type 2 tumours have a similar behaviour and natural history but, like the dualistic pathway relating to the pathogenesis of uterine carcinomas, is concerned with broad mechanisms of tumour development. Type 1 tumours, like colorectal adenocarcinomas, are considered to arise via a well defined adenomacarcinoma sequence from a benign precursor lesion and to evolve in a stepwise fashion. Many cases are associated with mutations in k-ras and b-raf. These are, in general, indolent tumours. There are obvious parallels with type 1 endometrial cancers that are also, in general, indolent and arise from a welldefined precursor (ie, atypical hyperplasia). In contrast, type 2 ovarian carcinomas are high-grade neoplasms that arise from an as yet undefined precursor lesion. They are often associated with p53 mutations. Again there are obvious parallels with type 2 endometrial cancers. The different categories of type 1 and type 2 ovarian carcinoma are listed in table 4; low-grade OSC is the prototype of type 1 carcinoma, and high-grade OSC is the prototype of type 2 carcinoma. Carcinosarcoma is considered a type 2 neoplasm since, in most cases, the epithelial component is high-grade serous in type. Moreover, similar to the corresponding uterine neoplasms, it is now accepted that in most cases the sarcomatous elements are derived from the carcinoma and the epithelial component is the driving force; in essence most represent metaplastic carcinomas, although the term carcinosarcoma is retained. ${ }^{88} 89$ It is recognised that there are some problems with the proposed classification in that some neoplasms do not fit easily into either type 1 or 2 (eg, clear cell carcinoma, although at present it is included in the type 1 category). It is also probable that in rare cases, a type 1 carcinoma can transform into a type 2 carcinoma (eg, low-grade OSC evolving into a high-grade OSC).

\section{CONCLUSIONS}

In summary, there have been significant recent developments regarding the pathogenesis and underlying molecular events in ovarian carcinomas; each of the major types has a different pathogenesis and is associated with distinct, but sometimes overlapping, molecular events. It is now widely accepted that there are two distinct types of OSC, termed low-grade and highgrade, and these may be viewed as the prototypical tumours in a broad dualistic classification of ovarian epithelial malignancy. Careful morphological examination combined, if necessary, with immunohistochemistry should result in accurate typing of ovarian carcinomas. Accurate and precise typing is necessary for clinical trials investigating whether different types of

Table 4 Categories of type 1 and type 2 ovarian carcinomas

\begin{tabular}{ll}
\hline Type 1 carcinomas & Type 2 carcinomas \\
\hline Low-grade serous & High-grade serous \\
Mucinous & Carcinosarcoma \\
Endometrioid & Undifferentiated \\
Clear cell & \\
Malignant Brenner & \\
\hline
\end{tabular}

\section{Take-home messages}

- Ovarian carcinomas comprise a heterogenous group of neoplasms, each with a different underlying pathogenesis and natural behaviour.

- There is considerable interobserver variation in the distinction between high-grade serous and endometrioid adenocarcinomas.

- In my opinion, most poorly differentiated ovarian adenocarcinomas are serous in type; WT1 immunohistochemical staining may be useful in confirmation.

- It is now clear that there are two distinct types of ovarian serous carcinoma, termed low-grade and high-grade serous carcinoma; these comprise two distinct tumour types rather than different grades of the same neoplasm.

- True clear cell carcinoma should be distinguished from clear cell areas within a serous or endometrioid adenocarcinoma.

carcinoma are best managed by alternative therapeutic regimes, both surgical and non-surgical. This may result in the development of specific therapies, possibly including targeted therapies, for management of the various types of ovarian cancer.

\section{Competing interests: None}

\section{REFERENCES}

1. Tavassoli FA, Devilee P, eds. World Health Organization Classification of Tumours Pathology and Genetics. Tumours of the Breast and Female Genital Organs. Lyon: IARC Press, 2003

2. Silverberg SG. Histopathologic grading of ovarian carcinoma: a review and proposal. Int J Gynecol Pathol 2000;19:7-15.

3. Shih IM, Kurman RJ. Ovarian tumorigenesis. A proposed model based on morphological and molecular genetic analysis. Am J Pathol 2004:164:1511-8.

4. Koonings PP, Campbell K, Mishell DR Jr, et al. Relative frequency of primary ovarian neoplasms: a 10-year review. Obstet Gynecol 1989;74;921-6.

5. Seidman JD, Horkayne-Szakaly I, Haiba M, et al. The histologic type and stage distribution of ovarian carcinomas of surface epithelial origin. Int J Gynecol Pathol 2004:23:41-4.

6. Hilton JL, Geisler JP, Rathe JA, et al. Inactivation of BRCA1 and BRCA2 in ovarian cancer. J Natl Cancer Inst 2002;94;1396-406.

7. Lee KR, Young $\mathrm{RH}$. The distinction between primary and secondary mucinous carcinomas of the ovary: gross and histologic findings in 50 cases. Am J Surg Pathol 2003:27:281-92.

8. Seidman JD, Kurman RJ, Ronnett BM. Primary and metastatic mucinous adenocarcinomas in the ovary: incidence in routine practice with a new approach to improve intraoperative diagnosis. Am J Surg Pathol 2003;27;985-93.

9. Lewis MR, Deavers MT, Silva EG, et al. Ovarian involvement by metastatic colorectal adenocarcinoma: still a diagnostic challenge. Am J Surg Pathol 2006;30;177-84.

10. McCluggage WG, Wilkinson N. Metastatic neoplasms involving the ovary: a review with an emphasis on morphological and immunohistochemical features. Histopathology 2005:47:231-47.

11. Berezowski K, Stasny JF, Kornstein MJ. Cytokeratins 7 and 20 and carcinoembryonic antigen in ovarian and colonic carcinoma. Mod Pathol 1996;9:1040-4.

12. Lagendijk JH, Mullink H, van Diest PJ, et al. Immunohistochemical differentiation between primary adenocarcinomas of the ovary and ovarian metastases of colon and breast origin. Comparison between a statistical and intuitive approach. J Clin Pathol 1999;52:283-90.

13. Park SO, Kim HS, Hong EK, et al. Expression of cytokeratins 7 and 20 in primary carcinomas of the stomach and colorectum and their value in the differential diagnosis of metastatic carcinomas to the ovary. Hum Pathol 2002;33;1078-85.

14. Ronnett BM, Zahn CM, Kurman RJ, et al. Disseminated peritoneal adenomucinosis and peritoneal mucinous carcinomatosis: a clinicopathologic analysis of 109 cases with emphasis on distinguishing pathologic features, site of origin, prognosis and relationship to 'pseudomyxoma peritonei'. Am J Surg Pathol 1995;19:1390-408.

15. Guerrieri C, Franlund B, Boeryd B. Expression of cytokeratin 7 in simultaneous mucinous tumors of the ovary and appendix. Mod Pathol 1995;8:573-6.

16. Ronnett BM, Shmookler BM, Diener-West M, et al. Immunohistochemical evidence supporting the appendiceal origin of pseudomyxoma peritonei in women. Int $\mathrm{J}$ Gynecol Pathol 1997;16:1-9.

17. Hart WR. Mucinous tumors of the ovary: a review: Int J Gynecol Pathol 2005;24:4 25. 
18. Brugghe J, Baak JP, Wiltshaw E, et al. Further evaluation of reproducibility and prognostic value of histologic typing and grading in FIGO stage I ovarian cancer patients without systemic locoregional adjuvant treatment. Int J Gynecol Cancer 1995;5:262-8.

19. Bertelsen K, Holund B, Andersen E. Reproducibility and prognostic value of histologic type and grade in early epithelial ovarian cancer. Int J Gynecol Cancer 1993;3:72-9.

20. Baak JP, Langley FA, Talerman A, et al. Interpathologist and intrapathologist disagreement in ovarian tumor grading and typing. Anal Ouant Cytol Histol 1986:8:354-7.

21. Cramer SF, Roth LM, Ulbright TM, et al. Evaluation of the reproducibility of the World Health Organization classification of common ovarian cancers. With emphasis on methodology. Arch Pathol Lab Med 1987;111:819-29.

22. Lund B, Thomsen HK, Olsen J. Reproducibility of histopathological evaluation in epithelial ovarian carcinoma. Clinical implications. APMIS 1991:99:353-8.

23. Sakamoto A, Sasaki H, Furusato M, et al. Observer disagreement in histological classification of ovarian tumors in Japan. Gynecol Oncol 1996;54:54-8.

24. Han G, Gilks CB, Leung $S$, et al. Interobserver variation in the diagnosis of ovarian clear cell carcinoma and mixed ovarian epithelial carcinomas with a clear cell component. Lab Invest 2007:200A

25. McCluggage WG, Lyness RW, Atkinson RJ, et al. Morphological effects of chemotherapy on ovarian carcinoma. J Clin Pathol 2002;55:27-31.

26. Sato $\mathbf{Y}$, Shimamoto T, Amada $S$, et al. Prognostic value of histologic grading of ovarian carcinomas. Int J Gynecol Pathol 2003;22:52-6.

27. Shimizu Y, Kamoi S, Amada S, et al. Toward the development of a universal grading system for ovarian epithelial carcinoma. I. Prognostic significance of histopathologic features - problems involved in the architectural grading system. Gynecol Oncol 1998;70:2-12

28. Shimizu Y, Kamoi S, Amada S, et al. Toward the development of a universal grading system for ovarian epithelial carcinoma: testing of a proposed system in a series of 461 patients with uniform treatment and follow-up. Cancer 1998;82:893-901.

29. Cho EY, Choi Y, Chae SW, et al. Immunohistochemical expression of the study of adhesion molecules in ovarian serous neoplasms. Pathol Int 2006;56:62-70.

30. McCluggage WG. WT1 is of value in ascertaining the site of origin of serous carcinomas within the female genital tract. Int J Gynecol Pathol 2004;23:97-9.

31. Shimizu M, Toki T, Takagi Y, et al. Immunohistochemical detection of the Wilms tumor gene (WT1) in epithelial ovarian tumors. Int J Gynecol Pathol 2000;19:158-63.

32. Al-Hussaini $\mathbf{M}$, Stockman A, Foster $\mathrm{H}$, et al. WT-1 assists in distinguishing ovarian from uterine serous carcinoma and in distinguishing between serous and endometrioid ovarian carcinoma. Histopathology 2004;44:109-15.

33. Goldstein NS, Uzieblo A. WT-1 immunoreactivity in uterine papillary serous carcinomas is different from ovarian serous carcinomas. Am J Clin Pathol 2002;117:541-5.

34. O'Neill CJ, McBride HA, Connolly LE, et al. High-grade ovarian serous carcinoma exhibits significantly higher p16 expression than low-grade serous carcinoma and serous borderline tumour. Histopathology 2007:50:773-9.

35. Vang R. Gown AM, Farinola $M$, et al. p16 expression in primary ovarian mucinous and endometrioid tumors and metastatic adenocarcinomas in the ovary: utility for identification of metastatic HPV-related endocervical adenocarcinomas. Am J Surg Pathol 2007;31;653-63.

36. Gilks CB. Subclassification of ovarian surface epithelial tumors based on correlation of histologic and molecular pathologic data. Int J Gynecol Pathol 2004:23:200-5.

37. Russell HE, McCluggage WG. A multistep model for ovarian tumorigenesis: the value of mutation analysis in the KRAS and BRAF genes. J Pathol 2004;203:617-9.

38. Singer G, Kurman RJ, Chang HW, et al. Diverse tumorigenic pathways in ovarian serous carcinoma. Am J Pathol 2002;160:1223-8.

39. Singer G, Shih IM, Truskinovsky A, et al. Mutational analysis of K-ras segregates ovarian serous carcinomas into two types: invasive MPSC (low-grade tumor) and conventional serous carcinoma. Int J Gynecol Pathol 2003:22:37-41.

40. Singer G, Stohr R, Cope L, et al. Patterns of p53 mutations separate ovarian serous borderline tumors and low and high grade carcinomas and provide support for a new model of ovarian carcinogenesis: a mutational analysis with immunohistochemical correlation. Am J Surg Pathol 2005;29:218-24.

41. Ho C-L, Kurman RJ, Dehari R, et al. Mutations of BRAF and KRAS precede the development of ovarian serous borderline tumors. Cancer Res 2004:64:6915-8.

42. Sieben NLG, Macropoulos P, Roemen GMJM, et al. In ovarian neoplasms, BRAF, but not KRAS, mutation are restricted to low-grade serous tumours. J Pathol 2004;202:336-40.

43. Feeley KM, Wells M. Precursor lesions of ovarian epithelial malignancy. Histopathology 2001:32:87-95.

44. Kindelberger DW, Lee Y, Miron A, et al. Intraepithelial carcinoma of the fimbria and pelvic serous carcinoma: Evidence for a causal relationship. Am J Surg Pathol 2007;31:161-9.

45. Lee $\mathbf{Y}$, Miron A, Drapkin R, et al. A candidate precursor to serous carcinoma that originates in the distal fallopian tube. J Pathol 2007:211:26-35.

46. Lee $\mathbf{Y}$, Medeiros $F$, Mindelberger $D$, et al. Advances in the recognition of tubal intraepithelial carcinoma: applications to cancer screening and the pathogenesis of ovarian cancer. Adv Anat Pathol 2006;13:1-7.

47. Medeiros $\mathbf{F}$, Muto MG, Lee $Y$, et al. The tubal fimbria is a preferred site for early adenocarcinoma in women with familial ovarian cancer syndrome. Am J Surg Pathol 2007;30:230-6.

48. Malpica A, Deavers MT, Lu K, et al. Grading ovarian serous carcinoma using a twotier system. Am J Surg Pathol 2004:28:496-504.
49. Malpica A, Deavers MT, Tornos C, et al. Interobserver variability of the two-tier system for grading ovarian serous carcinoma. Mod Pathol 2005;18:194A

50. Weir MM, Bell DA, Young RH. Grade 1 peritoneal carcinomas: a report of 14 cases and comparison with 7 peritoneal serous psammocarcinomas and 19 peritoneal serous borderline tumors. Am J Surg Pathol 1998:22:849-62.

51. O'Neill CJ, Deavers MT, Malpica A, et al. An immunohistochemical comparison between low-grade and high-grade ovarian serous carcinomas. Significantly higher expression of p53, MIB1, bcl2, her-2/neu and C-KIT in high-grade neoplasms. Am J Surg Pathol 2005:29:1034-41.

52. Dehari R, Kurman RJ, Logani S, et al. The development of high-grade serous carcinoma from atypical proliferative (borderline) serous tumors and low-grade micropapillary serous carcinoma: a morphologic and molecular genetic análisis. Am J Surg Pathol 2007;31:1007-12.

53. Ronnett BM, Kajdacsy-Balla A, Gilks CB, et al. Mucinous borderline ovarian tumors: points of general agreement and persistent controversies regarding nomenculature, diagnostic criteria, and behaviour. Hum Pathol 2004;35:959-60.

54. Rodriguez IM, Irving JA, Prat J. Endocervical-like mucinous borderline tumors of the ovary: a clinicopathologic analysis of 31 cases. Am J Surg Pathol 2004;28:1311-8.

55. Lee KR, Nucci MR. Ovarian mucinous and mixed epithelial carcinomas of mullerian (endocervical-like) type: a clinicopathologic analysis of four cases of an uncommon variant associated with endometriosis. Int J Gynecol Pathol 2003;22:42-51.

56. Tenti $\mathbf{P}$, Aguzzi A, Riva $\mathrm{C}$, et al. Ovarian mucinous tumors frequently express markers of gastric, intestinal and pancreaticobiliary epithelial cells. Cancer 1992;69:2131-42.

57. Vang $\mathbf{R}$, Gow AM, Wu LS, et al. Immunohistochemical expression of CDX2 in primary ovarian mucinous tumors and metastatic mucinous carcinomas involving the ovary: comparison with CK20 and correlation with coordinate expression of CK7. Mod Pathol 2006;19:1421-8

58. Vang R, Gown AM, Barry TS, et al. Cytokeratins 7 and 20 in primary and secondary mucinous tumors of the ovary: analysis of coordinate immunohistochemical expression profiles and staining distribution in 179 cases. Am J Surg Pathol 2006;30:1130-9.

59. Vang R, Gown AM, Barry TS, et al. Ovarian atypical proliferative (borderline) mucinous tumors: gastrointestinal and seromucinous (endocervical-like) types are immunophenotypically distinctive. Int J Gynecol Pathol 2006;25:83-9.

60. Vang R, Gown AM, Barry TS, et al. Immunohistochemistry for estrogen and progesterone receptors in the distinction of primary and metastatic mucinous tumors in the ovary: an analysis of 124 cases. Mod Pathol 2006;19:97-105.

61. Vang R, Gown AM, Zhao C, et al. Ovarian mucinous tumors associated with mature cystic teratomas: morphologic and immunohistochemical analysis identifies a subse of potential teratomatous origin that shares features of lower gastrointestinal tract mucinous tumors more commonly encountered as secondary tumors in the ovary. Am J Surg Pathol 2007;31:854-69.

62. Scott M, McCluggage WG. Current concepts in ovarian epithelial tumorigenesis: correlation between morphological and molecular data. Histol Histopathol 2006;21:81-92.

63. Cantrecasas $\mathbf{M}$, Villaneuva A, Matias-Guiu $\mathbf{X}$, et al. K-ras mutations in mucinous ovarian tumors: a clinicopathologic and molecular study of 95 cases. Cancer 1997:70:1581-6.

64. Takeshima Y, Amatya VJ, Dalmaru Y, et al. Heterogenous genetic alteration in ovarian mucinous tumors: application and usefulness of laser capture microdissection. Hum Pathol 2001:32:1203-8.

65. Gemignani ML, Schlaerth AC, Bogomolnly F, et al. Role of KRAS and BRAF gene mutations in mucinous ovarian carcinoma. Gynecol Oncol 2003;90:378-81.

66. Sainz DIC, Eichhorn JH, Rice LW, et al. Histologic transformation of benign endometriosis to early epithelial ovarian cancer. Gynecol Oncol 1996;60:238-44.

67. Stern RC, Dash R, Bentley RC, et al. Malignancy in endometriosis: frequency and comparison of ovarian and extraovarian types. Int J Gynecol Pathol 2001;20:133-9.

68. Bell KA, Kurman RJ. A clinicopathologic analysis of atypical proliferative (borderline) tumors and well-differentiated endometrioid adenocarcinomas of the ovary. Am J Surg Pathol 2000;24:1465-9.

69. Tornos C, Silva EG, Ordonez NG, et al. Endometrioid carcinoma of the ovary with a prominent spindle-cell component, a source of diagnostic confusion. Am J Surg Pathol 1995;19:1343-53.

70. Roth LM, Liban E, Czernobilsky B. Ovarian endometrioid tumors mimicking Sertoli and Sertoli-Leydig cell tumors. Sertoliform variant of endometrioid carcinoma. Cancer 1982:50:1322-31.

71. Young RH, Prat J, Scully RE. Ovarian endometrioid carcinomas resembling sex-cord stromal tumors. A clinicopathologic analysis of 13 cases. Am J Surg Pathol 1982;6:513-22.

72. Murray SK, Clement PB, Young RH. Endometrioid carcinomas of the uterine corpus with sex cord-like formations, hyalinization, and other unusual morphologic features: a report of 31 cases of a neoplasm that may be confused with carcinosarcoma and other uterine neoplasms. Am J Surg Pathol 2005;29:157-66.

73. Elishaev E, Gilks CB, Miller D, et al. Synchronous and metachronous endocervical and ovarian neoplasms: evidence supporting interpretation of the ovarian neoplasms as metastatic endocervical adenocarcinomas simulating primary ovarian surface epithelial neoplasms. Am J Surg Pathol 2005:29:281-94.

74. Lerwill MF, Young RH. Ovarian metastasis of intestinal-type gastric carcinoma: a clinicopathologic study of 4 cases with contrasting features to those of Krukenberg tumor. Am J Surg Pathol 2006;30:1382-8.

75. McCluggage WG, Young RH. Immunohistochemistry as a diagnostic aid in the evaluation of ovarian tumors. Semin Diagn Pathol 2005:22:3-32. 
76. Fragetta F, Pelosi G, Cafici A, et al. CDX2 immunoreactivity in primary and metastatic ovarian mucinous tumours. Virchows Arch 2003;443:782-6.

77. Logani S, Oliva E, Arnell PM, et al. Use of novel immunohistochemical markers expressed in colonic adenocarcinoma to distinguish primary ovarian tumors from metastatic colorectal carcinoma. Mod Pathol 2005;18:19-25.

78. Raspollini MR, Amunni G, Villanucci A, et al. Utility of CDX-2 in distinguishing between primary and secondary (intestinal) mucinous ovarian carcinoma: an immunohistochemical comparison of 43 cases. Appl Immunohistochem Mol Morphol 2004; 12:127-31.

79. Catasus L, Bussaglia E, Rodriguez I, et al. Molecular genetic alterations in endometrioid carcinomas of the ovary: similar frequency of $\beta$-catenin abnormalities but lower rate of microsatellite instability and PTEN alterations than in uterine endometrioid carcinomas. Hum Pathol 2004;35:1360-8.

80. Kennedy AW, Biscotti CV, Hart WR, et al. Ovarian clear cell adenocarcinoma. Gynecol Oncol 1989;32:342-9.

81. Tan DS, Kaye S. Ovarian clear cell carcinoma: a continuing enigma. J Clin Pathol 2007;60:355-60.

82. Cameron Rl, Ashe P, O'Rourke DM, et al. A panel of immunohistochemical stains assists in the distinction between ovarian and renal clear cell carcinoma. Int $J$ Gynecol Pathol 2003:22:272-6.
83. Eichhorn JH, Young RH. Transitional cell carcinoma of the ovary: a morphologic study with emphasis on differential diagnosis. Am J Surg Pathol 2004; 28:453-63.

84. Riedel I, Czernobilsky B, Lifschitz-Mercer B, et al. Brenner tumors but not transitional cell carcinomas of the ovary show urothelial differentiation: immunohistochemical staining of urothelial markers, including cytokeratins and uroplakins. Virchows Arch 2001:435:181-91.

85. Soslow RA, Rouse RV, Hendrickson MR, et al. Transitional cell neoplasms of the ovary and urinary bladder: a comparative immunohistochemical analysis. Int J Gynecol Pathol 1996:15:257-65.

86. Logani S, Oliva $\mathrm{E}, \mathrm{Amin} \mathrm{MB}$, et al. Immunoprofile of ovarian tumors with putative transitional cell (urothelial) differentiation using novel urothelial markers: histogenetic and diagnostic implications. Am J Surg Pathol 2003;27:1434-41.

87. Robey SS, Silva EG, Gershenson DM, et al. Transitional cell carcinoma in high-grade high-stage ovarian carcinoma. An indicator of favorable response to chemotherapy. Cancer 1989;65:939-47.

88. McCluggage WG. Malignant biphasic uterine tumours: carcinosarcomas or metaplastic carcinomas? J Clin Pathol 2002:55:321-5.

89. McCluggage WG. Uterine carcinosarcomas (malignant mixed mullerian tumors) are metaplastic carcinomas. Int J Gynecol Cancer 2002:12:687-90.

\section{Date for your diary}

\section{International Forum on Quality \& Safety in Health Care}

22-25 April 2008

Le Palais de Congrès de Paris

Paris, France

http://www.internationalforum.bmj.com

Why attend?

- Join over 1000 healthcare professionals from over 40 countries worldwide

- Learn from experienced leaders and improvement experts

- Find out what is current in quality and safety

- Gain new skills and tools for creating change in your organisation

- Take home practical solutions for improvement methods

- Network with like-minded colleagues

This is a premier event for those dedicated to improving quality and safety in healthcare. Our focus is on practical, take-home ideas that will leave you inspired to implement valuable, lasting change on your return to the workplace.

Register online from January 2008 onwards

For more information on the forum visit - http://www.internationalforum.bmj.com 